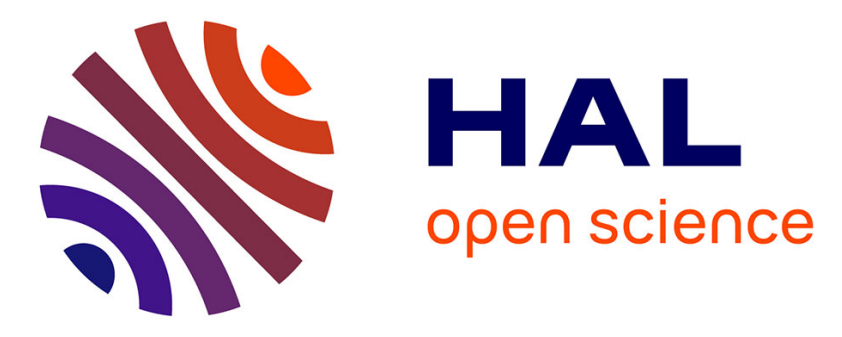

\title{
Engrailed protects mouse midbrain dopaminergic neurons against mitochondrial complex I insults
}

\author{
Daniel Alvarez-Fischer, Julia Fuchs, François Castagner, Olivier Stettler, \\ Olivia Massiani Beaudoin, Kenneth L Moya, Colette Bouillot, Wolfgang H \\ Oertel, Anne Lombès, Wolfgang Faigle, et al.
}

\section{To cite this version:}

Daniel Alvarez-Fischer, Julia Fuchs, François Castagner, Olivier Stettler, Olivia Massiani Beaudoin, et al.. Engrailed protects mouse midbrain dopaminergic neurons against mitochondrial complex I insults. Nature Neuroscience, 2011, 10.1038/nn.2916 . hal-00676206

\section{HAL Id: hal-00676206 https://hal.science/hal-00676206}

Submitted on 4 Mar 2012

HAL is a multi-disciplinary open access archive for the deposit and dissemination of scientific research documents, whether they are published or not. The documents may come from teaching and research institutions in France or abroad, or from public or private research centers.
L'archive ouverte pluridisciplinaire HAL, est destinée au dépôt et à la diffusion de documents scientifiques de niveau recherche, publiés ou non, émanant des établissements d'enseignement et de recherche français ou étrangers, des laboratoires publics ou privés. 


\section{Engrailed protects mouse midbrain dopaminergic neurons against mitochondrial complex I insults}

Daniel Alvarez-Fischer ${ }^{1,2,4, *}$, Julia Fuchs ${ }^{2, *}$, François Castagner ${ }^{2}$, Olivier Stettler ${ }^{2,3}$, Olivia Massiani Beaudoin ${ }^{2}$, Kenneth L. Moya ${ }^{2}$, Colette Bouillot ${ }^{2}$, Wolfgang H. Oertel ${ }^{4}$, Anne Lombès $^{5}$, Wolfgang Faigle ${ }^{6}$, Rajiv L. Joshi ${ }^{2, \$}$, Andreas Hartmann ${ }^{1, \$}$ \& Alain Prochiantz ${ }^{2, \$}$

${ }^{1}$ Centre de Recherche de l'Institut du Cerveau et de la Moelle Epinière UPMC/INSERM

UMR S 975; Groupe Hospitalier Pitié-Salpêtrière, 47-83 Boulevard de l'Hôpital, 75651 Paris Cedex 13, France.

${ }^{2}$ Collège de France, Center for Interdisciplinary Research in Biology (CIRB), Paris, F-75005, France; CNRS, UMR 7241, Paris, F-75005, France; INSERM, U1050, Paris, F-75005, France; University Pierre et Marie Curie, ED N¹58, Paris, F75005, France.

${ }^{3}$ present address: Université Paris Descartes, 46 rue des St Pères 75005 Paris.

${ }^{4}$ present address: Department of Neurology, Philipps-University, Marburg, Germany.

${ }^{5}$ INSERM U975, Hôpital de La Salpêtrière, Paris, France.

${ }^{6}$ Laboratoire de Spectrométrie de Masse Protéomique, Institut Curie, Paris, France.

* These authors contributed equally to this work.

${ }^{\$}$ Co-corresponding authors,

RLJ (rajiv.joshi@,college-de france.fr), AH (andreas.hartmann@psl.aphp.fr).

Correspondence should be addressed to AP:

(alain.prochiantz@,college-de-france.fr)

$+33(0) 144271555(\mathrm{Tel})$

+33 (0) 144271565 (Fax).

Collège de France, 11 place Marcelin Berthelot, 75231 Paris Cedex 05, France

The authors declare to have no conflicts of interest.

Number of Tables and Figures: 7 Figures

Number of pages: 22

Number of words for the main Manuscript text/Methods:

$3769 / 1701$

Supplementary Information :

6 Supplementary Figures 


\begin{abstract}
Mice heterozygous for homeobox gene Engrailed-1 display progressive loss of mesencephalic dopaminergic (mDA) neurons. We report that exogenous Engrailed-1 and Engrailed-2 (collectively Engrailed) protect $\mathrm{mDA}$ neurons from 1-methyl-4-phenyl-1,2,3,6tetrahydropyridine (MPTP), a mitochondrial complex I toxin used to model PD in animals. Engrailed enhances the translation of nuclear-encoded mRNAs for two key complex I subunits, Ndufs1 and Ndufs3, and increases complex I activity. Accordingly, in vivo protection against MPTP by Engrailed is antagonized by Ndufs1 siRNA. An association between Engrailed and complex I is further confirmed by the reduced expression of Ndufs 1 and Ndufs 3 in the substantia nigra pars compacta of Engrailed-1 heterozygous mice. Engrailed also confers in vivo protection against 6-hydroxydopamine and $\alpha$-synuclein-A30P. Finally, the unilateral infusion of Engrailed into the midbrain increases striatal dopamine content resulting in contralateral amphetamine-induced turning. Therefore, Engrailed is both a survival factor for adult mDA neurons and a regulator of their physiological activity.
\end{abstract}




\section{INTRODUCTION}

A key feature of Parkinson disease is the progressive demise of mesencephalic dopaminergic (mDA) neurons in the substantia nigra pars compacta (SNpc). The molecular mechanisms leading to mDA cell loss are not entirely elucidated. However, several studies indicate that mitochondrial complex I impairment plays a central role in this pathology ${ }^{1-3}$. In recent years, several transcription factors involved in $\mathrm{mDA}$ cell development have been identified ${ }^{4}$. Some of them remain expressed throughout life, including homeoproteins Engrailed-1 (En1) and Engrailed-2 (En2) ${ }^{5}$, but their adult functions are poorly understood.

We explored the role of En1/En2 (Engrailed) in the survival of adult mDA cells. The two proteins are equivalent in the midbrain ${ }^{6}$ and mice heterozygous for $E n 1\left(E n 1^{+/-} E n 2^{+/+}\right)$ display a gradual loss of mDA neurons in the SNpc and ventral tegmental area (VTA) ${ }^{7}$. This loss is more severe in the SNpc than in the VTA, a phenotype reminiscent of Parkinson disease, and mutant mice show behavioral (including motor) deficits. Importantly, the infusion of Engrailed into the SNpc arrests adult mDA neuronal loss in $E n 1^{+/-} \mathrm{En}^{+/+}$mice ${ }^{7}$. Engrailed, as many other homeoproteins, is internalized by live cells, gaining access to their cytoplasm and nucleus ${ }^{8}$.

This study investigated whether exogenously applied Engrailed protein is neuroprotective against MPTP (1-methyl-4-phenyl-1,2,3,6-tetrahydropyridine) and its metabolite $\mathrm{MPP}^{+}$(1-methyl-4-phenylpyridinium), a classical toxin-based Parkinson disease model and to better understand the neuroprotection mechanisms. In this context, it is to note that Engrailed, although a transcription factor, also regulates mRNA translation ${ }^{9,10}$. This regulation, first observed in growth cones, probably engages the mTOR pathway as it is accompanied by the phosphorylation of eIF4E and 4E-BP1, two key regulators of protein translation ${ }^{11}$. Regulating translation may be a property of several homeoproteins since many of them, including Engrailed, bind eIF4E ${ }^{12,13}$.

We thus examined whether Engrailed survival activity involves translational targets. In the case of mDA neurons, this hypothesis is supported by the presence of En1 protein in dendrites where no transcription takes place ${ }^{14}$. This led us to demonstrate that Engrailed regulates the translation of Ndufs 1 and Ndufs3, two mitochondrial complex I proteins and that this regulation participates in $\mathrm{mDA}$ neuron protection against cell death induced by complex I-specific neurotoxins. This protection by Engrailed was extended to the 6-hydroxydopamine

(6-OHDA) and $\alpha$-synuclein-A30P Parkinson disease models ${ }^{15,16}$. In addition we found that Engrailed infused in the midbrain of non-lesioned mice enhanced the levels of striatal 
dopamine (DA) and induced associated motor activity, suggesting a physiological function for a homeoprotein transcription factor in the adult brain.

\section{RESULTS}

\section{Engrailed protects mDA neurons against complex I toxins}

As a first in vitro approach to examine if Engrailed protected mDA neurons in experimental Parkinson disease models, embryonic ventral midbrain cells were dissociated at E14.5 and cultured for three days before the addition of $\mathrm{MPP}^{+}(3 \mu \mathrm{M})$ for two days, with or without Engrailed. Ten days after plating, the number tyrosine hydroxylase-labeled neurons was 2,003 \pm 110 in control cultures and $\mathrm{MPP}^{+}$decreased this number by $85 \%(86.73 \pm 1.75)$. En 1 and En2 similarly enhanced mDA cell survival by two-fold (Fig. 1a) with a dose-dependent protection and a maximal effect between 0.3 and $3 \mathrm{nM}$ (Fig. 1b). EnSR, an En2 internalization deficient mutant ${ }^{9}$ had no effect on $\mathrm{mDA}$ cell survival (Fig. 1a) indicating that survival activity requires internalization. The number of NeuN-positive cells (a neuron specific nuclear protein) remained unaffected in all conditions (Fig. 1c). $\mathrm{MPP}^{+}$is selectively captured by the dopamine transporter (DAT), explaining the specific loss of $\mathrm{mDA}$ neurons. We therefore verified that Engrailed does not protect mDA cells by decreasing DAT activity

\section{(Supplementary Fig. 1).}

Because Engrailed is expressed in a large majority of embryonic midbrain neurons in culture, we examined its protective effect against rotenone, a complex I inhibitor not selective for mDA neurons ${ }^{17}$. Rotenone $(50 \mathrm{nM})$ kills $37.8 \% \pm 5.5 \%$ of TH-positive (Fig. 1d) and $18.0 \% \pm 2.9 \%$ (Fig. 1e) of NeuN-positive neurons. Engrailed alone was without effect on the number of NeuN- and mDA cells but fully protected the two populations of neurons against rotenone (Fig. 1d,e). In contrast, Engrailed was not effective against 3-nitropropionic acid (3NP), a complex II toxin. The number of tyrosine hydroxylase- and NeuN-positive cells was reduced by $3-\mathrm{NP}$ (by $36.6 \% \pm 1.9 \%$ and $28.8 \% \pm 1.9 \%$, respectively) with no protection by Engrailed (Fig. 1f,g). Engrailed therefore protects embryonic midbrain neurons against complex I but not complex II toxins.

\section{Engrailed enhances the translation of complex I subunits}

Given that internalized Engrailed regulates translation in growth cones ${ }^{9,10}$, we hypothesized that local mRNA translation in response to Engrailed internalization may participate in its protective effect. In a first approach, adult midbrain synaptoneurosomes (a fraction enriched in synaptic terminals) were treated with En1 $(15 \mathrm{nM})$ or vehicle for $1 \mathrm{~h}$ at $37^{\circ} \mathrm{C}$ in the 
presence of ${ }^{35} \mathrm{~S}$-methionine/cysteine and newly synthesized En1-regulated proteins were identified by mass spectrometry.

Among 26 proteins identified, 16 were localized to mitochondria, including Ndufs1, a key subunit of mitochondrial complex I. Most mitochondrial proteins are encoded by nuclear genes and translated from mRNAs surrounding the organelle ${ }^{18}$. To further investigate Engrailed activity on local translation of complex I proteins, complex I was immunoprecipitated from Engrailed- or vehicle-treated radiolabeled synaptoneurosomes. Of 7 protein bands verified by mass spectroscopy, Engrailed increased the synthesis of Ndufs1 $(+43 \%)$ and Ndufs3 (+68\%) (Fig. 2a,b), two key proteins for complex I turnover and activity $19,{ }^{20}$ Immunoprecipitation of complexes II and $\mathrm{V}$ revealed no obvious changes after Engrailed treatment (Supplementary Fig. 3). Finally, complex I, but not complex IV, activity was increased by $20 \%$ in Engrailed-treated synaptoneurosomes, an increase reflected at the level of mitochondrial metabolism measured by citrate synthase activity (Fig. 2c).

Accordingly, Engrailed ( $3 \mathrm{nM}$ for $4 \mathrm{~h})$ increased the levels of Ndufs 1 and Ndufs $3(169 \% \pm$ $16 \%$ and $363 \% \pm 25 \%$, respectively; Fig. 3a,b) in midbrain cultures. The greater change in cells compared to synaptoneurosomes could reflect the fact that all midbrain embryonic neurons express Engrailed, whereas synaptoneurosomes are heterogeneous. These increases were not observed in the presence of anti-Engrailed antibodies indicating that Engrailed is the active entity. Ndufs 1 and Ndufs 3 increases were maintained in the presence of the transcription inhibitor actinomycin D $(5 \mu \mathrm{g} / \mathrm{ml})$, and are thus not dependent on transcriptional activity (Fig. 3a,b). Interestingly, Engrailed did not alter the levels of CoxIV, a component of complex IV of the respiratory chain (Fig. 3c).

To further verify that Ndufs 1 and Ndufs3 are part of an Engrailed-regulated pathway we quantified their expression in the SNpc of $E n 1^{+/} E n 2^{+/+}$one-year-old mice and their wildtype littermates. Ndufs1 and Ndufs3 immunoreactivity in mDA neurons were significantly decreased in the SNpc of $E n 1^{+/-} \mathrm{En}^{+/+}$mice $(25.39 \% \pm 5.76 \%$ and $24.05 \% \pm 7.26 \%$, respectively, $P<0.05 ; n=4$ animals per group) (Fig. 4a,b). No change of expression was observed for CoxIV (Fig. 4b). Ndufs3 expression showed no change in the oculomotor nucleus (Fig. 4b), a mesencephalic structure where Engrailed is not expressed. Nor were there any changes in the VTA (Supplementary Fig. 4). Finally, double immunofluorescence confirmed a $21.26 \% \pm 3.3 \%\left(P<0.01, n=4 E n 1^{+/-} E n 2^{+/+}\right.$and $n=4 w t$ littermates $)$ decrease in Ndufs 3 expression specifically in tyrosine hydroxylase-expressing neurons from $\mathrm{EnI}^{+/-} \mathrm{En}^{+/+}$ mice (Fig. 4c,d). All in all, these results demonstrate that Engrailed regulates the local 
translation of important mitochondrial complex I proteins during development and in the adult.

\section{Engrailed protects MDA neurons against MPTP in vivo}

$\mathrm{C} 57 \mathrm{Bl} / 6$ mice were unilaterally infused dorsal to the SNpc with a 1:1 mixture of En1/En2 (4.5 $\mu \mathrm{M}$ in the pump) or saline (sham) from days 1 to 14 , and MPTP or saline was administrated intraperitoneally (i.p.) daily on days 5 to 9 (Fig. 5a). In these conditions, Engrailed diffuses into the SNpc and VTA and is internalized by most neurons in the region ${ }^{7}$.

Engrailed or sham infusion had no effect on tyrosine hydroxylase-positive cell number in mice treated i.p. with saline. The number of $\mathrm{mDA}$ cells in the SNpc of non-infused (contralateral) side, sham-infused, and Engrailed-infused sides of mice treated i.p. with saline was 5,687 \pm 33 (Fig. 5b). In MPTP administered mice the number of tyrosine hydroxylasepositive neurons decreased by $32 \% \pm 3.1 \%(P<0.01)$. Infusion of Engrailed partially protected against MPTP since the number of tyrosine hydroxylase-positive cells was decreased by only $15.6 \% \pm 3.3 \%$ (48.7\% protection), comparing Engrailed-infused side to the non-infused side (same animals) or to both sides of sham-infused animals $(P<0.01)$ (Fig. 5d). The number of tyrosine hydroxylase-negative neurons per side ranged from $1,780 \pm 194$ to $1,970 \pm 170$ and did not differ significantly between the conditions (Nissl staining, Supplementary Fig. 5). Therefore, the higher number of tyrosine hydroxylase-positive cells in Engrailed-infused tissues reflects cell survival and not an up-regulation of tyrosine hydroxylase expression.

To test whether Ndufs1 up-regulation is necessary for Engrailed-mediated mDA neuron protection, we co-infused a cell permeable, Penetratin-coupled siRNA ${ }^{21}$ against Ndufs1 together with Engrailed, and administered systemic MPTP. Penetratin is a cell penetrating peptide used to transport cargoes into live cells ${ }^{22}$. We first determined conditions in which down-regulation of Ndufs1 expression by the siRNA is significant but moderate enough not to jeopardize cell survival (Supplementary Fig. 6). MPTP decreased the number of TH-positive neurons by $36 \% \pm 3.7 \%$ (Fig. 5c) and Engrailed (with a control siRNA) limited cell death to $27 \% \pm 4.04 \%$ (Fig. 5e), a protective effect fully abolished by a siRNA directed against Ndufs1 (Fig 5e). These data confirm that Ndufs1 translation is part of the Engrailed neuroprotection pathway.

\section{Engrailed increases striatal DA in vivo}

To examine the functional consequences of Engrailed-mediated protection of mDA neurons, we measured striatal DA in Engrailed- or sham-infused animals injected i.p. with MPTP or 
saline. As expected, striatal dopamine levels were decreased in both ipsi- and contralateral sides in sham-infused/MPTP-injected animals as compared to sham-infused/saline-injected controls, reflecting mDA cell loss (Fig. 6a). In contrast, ipsilateral striatal dopamine content in Engrailed-infused mice injected with MPTP remained in the range of that found in shaminfused/saline-injected controls. Thus, Engrailed protected against MPTP-induced striatal dopamine decrease.

Dopamine levels in the Engrailed-infused side of MPTP-injected animals were higher $(>100 \%$ of control) than expected given a protection of $50 \%$ of $\mathrm{mDA}$ neurons, suggesting that Engrailed not only provided neuroprotection, but also directly enhanced dopamine synthesis. To test this hypothesis, dopamine levels were measured in the striatum of Engrailed-infused mice injected with saline. While the number of mDA cells in the SNpc did not change (Fig. 5c), dopamine levels were increased by more than 50\% (Fig. 6a).

This increase in striatal dopamine thus reflects both a higher number of surviving mDA neurons (in MPTP-treated animals) and a higher dopamine content per terminal (in MPTP- and in saline-injected animals). We thus used dopamine content to further analyze the role of complex I in Engrailed activity. MPTP alone reduced striatal dopamine by 80 to $90 \%$ (Fig. 6b), and Engrailed infused in presence of a control siRNA rescued DA content to 35\% of control values whereas Ndufs1 siRNA fully antagonized this rescue. This confirmed that Engrailed doubles dopamine striatal concentrations (true for a $50 \%$ and $80 \%$ reduction, compare Fig. 6a and 6b), and that this effect depends on Ndufs1 translation.

\section{Unilateral Engrailed infusion alters turning behavior}

Animals treated systemically with MPTP or saline and infused in the midbrain with different compounds were analyzed for amphetamine-induced turning behavior at day 20 (see Fig. 5a). Mice injected with MPTP and infused with Engrailed and a control siRNA turn significantly toward the contralateral side $(-5.83 \pm 2.09$ net turns/min) compared to animals injected i.p. with saline and infused with saline $(-0.02 \pm 0.83$ net turns/min, $P<0.01)$ or injected with MPTP and infused with saline $(-0.23 \pm 0.76$ net turns $/ \mathrm{min}, P<0.05)$.

After MPTP intoxication, Ndufs1 siRNA injected into the SNpc abolishes the amphetamine-induced turning observed after Engrailed and control siRNA infusion $(0.13 \pm$ 1.19 net turns $/ \mathrm{min}$ versus $-5.83 \pm 2.09$ net turns/min) (Fig. 6c). MPTP injected animals infused with Ndufs 1 siRNA or saline injected animals infused with control siRNA did not show preferential turning $(-2.37 \pm 0.96$ net turns $/ \mathrm{min}$ and $-1.04 \pm 0.88$ net turns $/ \mathrm{min}$, respectively). Since siRNAs at the concentration used for these experiments have no effect of 
their own on dopamine levels or turning behavior, we conclude that Engrailed-induced mDA survival, dopamine synthesis and turning involve an increase in Ndufs1 expression.

Given that Engrailed infusion into the SNpc of control animals dramatically increases striatal dopamine levels, the effect of Engrailed on turning behavior was tested. As shown in Figure 6d, Engrailed-infused mice turned preferentially contralateral to the side of infusion ($3.79 \pm 0.58$ net turns $/$ min versus $-0.65 \pm 0.37$ net turns $/$ min for sham-infused mice $P<0.001$ ). The non-internalized En2SR variant had no effect (not shown), indicating that internalization of Engrailed is necessary for its protective and physiological effects. In conclusion, these results confirm that Engrailed, in addition to its survival effects, has a physiological function in dopaminergic activity.

\section{Engrailed protects mDA neurons in other Parkinson models}

Although MPTP intoxication is a widely used Parkinson disease model ${ }^{1}$, we examined whether Engrailed protects mDA neurons in two other models. We first used unilateral injection of 6-hydroxydopamine (6-OHDA) in the striatum, which provokes a Wallerian-like retrograde degeneration of the nigro-striatal dopamine pathway ${ }^{15}$ leading to $\mathrm{mDA}$ cell death. 6 -OHDA injection is followed 2 weeks later by the death of $60 \%$ of the mDA neurons in the SNpc but the infusion of Engrailed in the midbrain reduces cell death to less than $20 \%$ (Fig. 7a).

The second model is the injection of cell-permeable mutated $\alpha$-synuclein-A30P in the SNpc recently used to generate new rodent Parkinson disease models on a relatively short time-scale ${ }^{16}$. The in vitro toxicity of $\alpha$-synuclein-A30P on midbrain neurons in culture was fully antagonized by the addition of En1 (not shown). In vivo, the injection of the highly toxic $\alpha$-synuclein-A30P mutant in the SNpc led to a $40 \%$ decrease in TH cell number after 2 weeks (Fig. 7b). This cell death was fully antagonized by Engrailed infusion in the ventral midbrain immediately after $\alpha$-synuclein-A30P injection (Fig.7b).

These observations demonstrate that Engrailed confers neuroprotection to $\mathrm{mDA}$ neurons in three established Parkinson disease models.

\section{DISCUSSION}

Midbrain dopaminergic cell survival is compromised in mice with one dysfunctional Engrailed allele ${ }^{5,7}$ and the local infusion of Engrailed in the midbrain halts mDA cell death in En1 heterozygous mice ${ }^{7}$. It is noteworthy that despite the absence of Engrailed mutations in familial Parkinson disease, a genetic link between Engrailed and the risk for sporadic 
Parkinson disease has been postulated ${ }^{23}, 24$. We now report that exogenously applied Engrailed, which enters live cells, increases complex I activity and protects mDA neurons against $\mathrm{MPP}^{+} / \mathrm{MPTP}$ neurotoxicity in vitro and in vivo. This study also establishes a causal link between Engrailed-driven protection against $\mathrm{MPP}^{+} / \mathrm{MPTP}$ and the translation of complex I mitochondrial proteins, in particular Ndufs1.

Local translation is an important physiological response to local cues and stimulation ${ }^{11,}$ 25. Of particular relevance to this study is that Engrailed axon guidance activity requires its internalization and local protein translation ${ }^{9,10}$. The present work raises the possibility that Engrailed locally regulates translation of mRNAs encoding mitochondrial proteins. In fact, given the high number of mitochondria present in synapses and growth cones, the finding that the translation of mitochondrial mRNAs is regulated locally is not surprising ${ }^{26}$.

Mitochondrial impairment in Parkinson disease is suggested by several observations. First, complex I activity is reduced in the brains of patients ${ }^{3}$. Second, MPTP in mice or nonhuman primates selectively kills mDA neurons through inhibition of complex I ${ }^{1}$. Third, genetic studies in familial forms of Parkinson implicate mitochondrial dysfunctions since mutated nuclear genes encoding PINK1, Parkin, $\alpha$-synuclein, DJ-1 and LRRK2 all directly or indirectly affect mitochondrial physiology ${ }^{27,28}$. This list underscores the importance of this organelle, and of complex I activity in Parkinson disease.

Mammalian mitochondrial complex I is an assembly of 45 subunits, 7 of which are encoded by mitochondrial DNA and the remainder by the nuclear genome. Its catalytic core comprises 14 nuclear-encoded subunits among which, Ndufs1 and Ndufs3 are key subunits for complex I assembly and activity ${ }^{19,29,30}$. The observation that Ndufs1 and Ndufs3 are specifically down-regulated in mDA neurons in the SNpc of $E n 1^{+/-} E n 2^{+/+}$mice strengthens the correlation between the mDA neuron degeneration observed in $E n 1^{+/-} E n 2^{+/+}$mice ${ }^{7}$ and a local decrease in Ndufs1 and Ndufs3. Ndufs 1 is a particularly attractive Engrailed target since its cleavage by caspase- 3 is at the origin of mitochondrial changes associated with cell death 19. In this report, for practical reasons (siRNA design and controlled down-regulation of Ndufs1 expression), we focused on siRNA-mediated Ndufs1 manipulation. This does not mean that other complex I subunits are not also downstream targets of the Engrailed survival pathway.

Given the importance of mitochondria and complex I activity in Parkinson disease ${ }^{1,31}$, protection of mDA neurons by Engrailed through translational regulation of complex I proteins suggested that Engrailed may be effective in several Parkinson disease models. This is confirmed by the protective activity of Engrailed in the 6-OHDA and $\alpha$-synuclein models. 
It is noteworthy that 6-OHDA induces a retrograde degeneration when injected into the striatum, a phenomenon taking place in Parkinson disease ${ }^{32}$. The injection of toxic $\alpha$ synuclein into the $\mathrm{SNpc}^{16}$ is particularly pertinent since it mimics a mutation found in the human and takes advantage of the "prion-like" character of the protein ${ }^{33}$. In our hands, the injection of the cell-permeable $\alpha$-synuclein A30P induced the death of $40 \%$ of the mDA cells in the SNpc after 2 weeks and this toxicity was entirely blocked by Engrailed-1.

Other transcription factors important for mDA cell development are also expressed in adulthood and might contribute to Parkinson disease. For instance, the conditional knockout of Nurr1 in the adult leads to a slow and progressive loss of mDA neurons ${ }^{34}$. Similarly, Otx2 may function as a survival factor for mDA neurons in the VTA ${ }^{35,36}$ that are relatively spared in $E n 1^{+/-} E n 2^{+/+}$mice and less dependent on Enl expression. One can imagine using exogenous Otx2 to rescue VTA mDA neurons, an approach validated in a mouse model of glaucoma ${ }^{37,38}$.

Finally, Engrailed infused into the midbrain increases striatal dopamine levels, suggesting a physiological function in the regulation of nigrostriatal activity beyond neuroprotection. Indeed, the preferential turning towards the side contralateral to its infusion reflects this Engrailed-driven enhanced nigrostriatal function. It is of note that similarly to the protective activity against MPTP toxicity, this function is abolished when Ndufs 1 synthesis is inhibited, suggesting that several Engrailed functions in the mDA pathway involve its ability to regulate mitochondrial activity.

The notion that Engrailed is a regulator of mDA physiology in the adult allows one to consider homeoproteins from a non-developmental point of view. Given that En1 was detected in the dendrites of $\mathrm{mDA}$ neurons in vivo ${ }^{14}$, we propose that Engrailed in $\mathrm{mDA}$ dendrites acts to regulate local protein synthesis, in particular that of proteins participating in mitochondrial activity, in response to physiological stimulations.

In addition to Engrailed, other homeoproteins can regulate translation 9, 12, 39 and the binding to eIF4E is a characteristic shared by many of them ${ }^{39}$. This raises the possibility that similar mechanisms involving other homeoproteins and other cell types could be involved in disorders associated with mitochondrial dysfunction. To further widen the context, an unsuspected role in the regulation of mitochondrial activity has recently been reported for other transcription factors that engage different mechanisms. It was shown for instance that Stat3, within mitochondria, interacts with complex I and complex II, and regulates mitochondrial activity ${ }^{40}$. Similarly, MEF2D activates the transcription of ND6, a mitochondria-encoded complex I subunit ${ }^{41}$. 
In conclusion, it is tempting to propose that the present findings, beyond their basic biological interest, open new therapeutic perspectives. It is in particular noteworthy that, would Engrailed be considered as a putative therapeutic protein, it could not only protect neurons that otherwise would undergo degeneration but also increase the functional output of the remaining neurons.

\section{ACKNOWLEDGEMENTS}

This work was supported by Agence Nationale pour la Recherche (ANR-06-013-01), the Michael. J. Fox Foundation (MJFF), Fondation de France (Physiopathology of Parkinson disease) and the European Community (FP7 222999, mdDANeurodev project). DAF was funded by MJFF, University Medical Center Giessen and Marburg (UKGM) and the German Academic Exchange Service (DAAD). The CIRB group is part of a Global Research Laboratory (KAIST, South-Korea) and a Foundation for Medical Research (FRM) team. JF was funded by the German Research Foundation (DFG), the MJFF, FRM and NERF (Ile de France). AH was temporarily supported by INSERM. We thank E. Ipendey for her technical help. Confocal imaging and quantification were performed by V. Mignon and Dr B. Saubaméa (Imaging facilities, IFR71-IMTCE, Faculty of Pharmacy, Paris Descartes University). We thank the Laboratory of Mass Spectrometry and Proteomics, Institut Curie, Paris, France for assistance. We are indebted towards Annick Prigent, Etienne Hirsch, Patrick Michel and Michel Volovitch for their intellectual input.

\section{AUTHOR CONTRIBUTIONS}

D.A.F., J.F., F.C. O.M.B., R.L.J. performed experiments to study En survival activity. O.S., C.B., K.L.M., J.F., O.M.B., R.L.J. examined En translational targets. W.F. helped with mass spectroscopy. A.L. measured complex I activity. W.H.O. participated in discussions. J.F. D.A.F., R.L.J., A.H., A.P. designed the experiments and interpreted the results. D.A.F., J.F., R.L.J., A.P. wrote the manuscript.

\section{COMPETING FINANCIAL INTERESTS}

The authors declare no competing financial interests.

\section{FIGURE LEGENDS}


Figure 1 Engrailed protects against complex I, but not against complex II inhibition (a) Engrailed protects cultured embryonic midbrain TH-positive neurons against $\mathrm{MPP}^{+}$. En1 or En2 (3 nM), but not a non-internalized mutant form of En2, EnSR, enhanced by two fold the survival of $\mathrm{TH}$-positive cells after $\mathrm{MPP}^{+}(3 \mu \mathrm{M})$ treatment. Data are expressed as percentage of vehicle (mean \pm s.e.m.), which corresponds to 2,003 $\pm 110 \mathrm{TH}$-positive cells per well. $* P<0.05 ; n=5-10$. Under these culture conditions, about $80 \%$ of the cells were neurons (Supplementary Fig. 2).

(b) Dose-dependent protection of Engrailed against $\mathrm{MPP}^{+}$with maximal protective effects between 0.3 and $3 \mathrm{nM}$. Data are expressed as a percentage of $\mathrm{MPP}^{+}$treatment (mean \pm s.e.m.). ${ }^{*} P<0.05 ; n=5-6$.

(c) The total number of cultured neurons (NeuN-positive cells), 277,000 $\pm 3,450$ (set at 100\%) is not modified by $\mathrm{MPP}^{+}$and/or Engrailed treatments.

(d,e) Engrailed fully protects TH-positive and the total neurons (NeuN-positive) against rotenone, an unspecific complex I inhibitor. Rotenone treatment (50 nM, days 4-5) led to a $40 \%$ (mean \pm s.e.m.) loss of TH-positive cells (d) and 18\% loss of NeuN-positive cells (e). $* P<0.05 ; n=5-7$.

$(\mathbf{f}, \mathbf{g})$ The addition of complex II inhibitor 3-NP $(100 \mu \mathrm{M})$ between days 4-6 in vitro leads to a $36.6 \% \pm 1.9 \%$ (mean \pm s.e.m.) reduction of TH-positive neurons (f) and to a $28.8 \% \pm 1.9 \%$ reduction of NeuN-positive neurons (g), without any protective effect of Engrailed. Data are expressed as percentage of control, which corresponds to about 2000 TH-positive and $270,000 \mathrm{NeuN}$-positive cells per well, respectively. n.s., non-significant; ${ }^{*} P<0.001 ; n=7-13$.

Figure 2 Engrailed increases the translation of specific complex I subunits and complex I activity

(a) Metabolic labeling of midbrain synaptoneurosomes followed by complex I immunocapture, SDS-PAGE analysis and mass spectrometry show an up-regulation by En1 of complex I subunits, including Ndufs 1 and Ndufs3.

(b) Densitometric quantification of complex I subunits specifically identified by mass spectrometry and western blotting comparing the intensity of complex I subunit proteins in synaptoneurosomes treated with En1 or vehicle (control).

(c) Engrailed enhances complex I activity. Complex I activity, but not complex IV activity, is increased by $20 \%$ in Engrailed-treated synaptoneurosomes. Citrate synthase activity, an index of metabolic activity, is also increased by Engrailed. Data are expressed as percentage of vehicle-treated synsaptoneurosomes (mean \pm s.e.m.), which correspond to a NADH oxidation 
rate of $188.6 \pm 4.7 \mu \mathrm{mol} / \mathrm{min} / \mathrm{mg}$ protein for complex I, cytochrome $c$ oxidation rate of 375.8 $\pm 5.3 \mu \mathrm{mol} / \mathrm{min} / \mathrm{mg}$ protein for complex IV and acetyl-CoA conversion rate of 1,028.9 \pm 13.7 $\mu \mathrm{mol} / \mathrm{min} / \mathrm{mg}$ protein for citrate synthase, respectively. n.s., non-significant; ${ }^{*} P<0.05 ; n=3$ 4.

Figure 3 Engrailed enhances Ndufs 1 and Ndufs3 levels in primary midbrain neuron cultures (a,b) En1 $(3 \mathrm{nM})$ or vehicle (control) was added for $4 \mathrm{~h}$ to primary mesencephalic neurons in culture (5DIV), and the steady state levels of Ndufs1, Ndufs3 and actin (gel loading control) were estimated by western blotting. Densitometric quantification (mean \pm s.e.m.) revealed a significant increase in both, Ndufs1 (a) and Ndufs3 (b) proteins, upon En1 treatment. This increase was completely blocked by preincubation of En1 with an anti-Engrailed antibody $\left(\mathrm{Ab} 86 / 8 ;{ }^{7}\right)$ and was unaffected by an actinomycin $\mathrm{D}$ (actD) treatment $(5 \mu \mathrm{g} / \mathrm{ml})$, sufficient to block transcription (verified by Q-RT-PCR; data not shown).

(c) Under the same conditions, the amounts of Cox IV remained unaffected. n.s., nonsignificant; $* P<0.05 ; n=5$.

Figure 4 Ndufs 1 and Ndufs 3 expression levels are decreased in $E n 1^{+/} E n 2^{+/+}$mice

(a) Immunohistochemical analysis of Ndufs1 staining in the SNpc. Free-floating cryosections of the entire midbrain of one-year old $\mathrm{EnI}^{+/-} \mathrm{En2}^{+/+}$animals and wt littermates were stained for Ndufs1 (and Ndufs3, not shown). Neurons of the SNpc of mutant mice show a decrease in the amount of the proteins. Scale bars correspond to $100 \mu \mathrm{m}$.

(b) Quantification of Ndufs1, Ndufs3 and Cox IV staining. Optical density per neuron in the SNpc was measured, demonstrating a decrease in Ndufs1 (25.39 \pm 5.76 ; mean \pm s.e.m.) and Ndufs $3(24.05 \% \pm 7.26 \%)$ protein. The intensity of Cox IV staining was identical in mutant and wt mice. ${ }^{*} \mathrm{P}<0.05 ; \mathrm{n}=4$ Ndufs 3 staining intensity analyzed in the nucleus of the oculomotor nerve showed no alteration in $E n 1^{+/-} E n 2^{+/+}$animals $* \mathrm{P}<0.05 ; \mathrm{n}=4$.

(c) Double-fluorescence immunostaining of Ndufs3 and $\mathrm{TH}$ on free-floating coronal vibratome sections of one-year-old $\mathrm{EnI}^{+/-} \mathrm{En}^{+/+}$mice and wt littermates (confocal sections). (d) Ndufs3 staining intensity was decreased by $21.26 \% \pm 3.3 \%$ (mean \pm s.e.m.) in THpositive neurons compared to wt animals. $* \mathrm{P}<0.01 ; \mathrm{n}=3$.

Figure 5 Engrailed protection against MPTP is Ndufs1-dependent 
(a) Experimental scheme. C57B1/6 mice were infused with a mixture of En1/En2 (1:1, $4.5 \mu \mathrm{M}$ total) for 14 days dorsal to the SNpc. MPTP (30 mg/kg) or saline was injected (i.p.) for 5 consecutive days starting on day 5 after pump implantation, ${ }^{42}$ and killed-on day 21.

(b) Compared to the sham-infused side, the Engrailed-infused side of MPTP-injected animals shows a partial preservation of TH-positive neurons in the SNpc (peroxydase immunostaining). Scale bar, $100 \mu \mathrm{m}$.

(c) Representative images of the ipsilateral (Engrailed plus siRNA infused side) and the contralateral (non-infused) side of the same animal.

(d) The non-infused side of control mice injected with saline was set at $100 \%$ of TH-positive cells and used for comparison with all other conditions. MPTP decreased the number of THpositive cells by $32.1 \% \pm 3.1 \%$ (mean \pm s.e.m.) on sham-infused and contralateral side $\left({ }^{*} P<0.01\right)$. The infusion of En1/En2 reduced cell loss to $15 \% \pm 3.4 \%(\# P<0.01)$. Data are expressed as percentage of control, $n=6-10$ animals/group. c, contralateral, non-infused side; S, sham-infused side; En, Engrailed-infused side. The number of TH negative neurons remained constant in all conditions (Supplementary Fig. 5).

(e) The number of TH-positive neurons in the MPTP-treated animals (3964 \pm 300.2$)$ is decreased by $36 \% \pm 3.7 \%$. Engrailed protection against MPTP $(+26.1 \%)$ was abolished by the Ndufs 1 siRNA $(4065 \pm 414.1)$ but not by a control siRNA $(4556 \pm 251.8)$. Data are expressed as percentage of control. ${ }^{*} P<0.05 ; \mathrm{n}=4-7$. c, contralateral.

Figure 6 Engrailed-driven increases in striatal DA and turning behavior after MPTP are Ndufs1-dependent

(a) MPTP induces a $46 \% \pm 2.3 \%$ (mean \pm s.e.m.) decrease in striatal DA content compared to non-lesioned animals. Engrailed infusion fully antagonizes this decrease $(115.25 \% \pm$ 19.23\%). Saline-injected control mice infused with Engrailed show a $77.5 \% \pm 20.42 \%$ increase in striatal dopamine compared to baseline levels (saline-infused mice and the noninfused contralateral side of the same animals). c, contralateral side; S, sham-infused; En, Engrailed-infused. ${ }^{*} P<0.05 ; \# P<0.05 ; \mathrm{n}=4-8$.

(b) In conditions where MPTP decreased DA 90\%, Engrailed infusion enhanced DA concentration by 3.5 fold ( $35 \%$ of saline-injected, sham-infused controls). Protection was fully blocked by the Ndufs 1 siRNA but not by a control siRNA (saline-injected, sham-infused controls set as 100\%, $\mathrm{n}=5-7$ ). c, contralateral side; S, sham-infused; En, Engrailed-infused. 
(c) Engrailed induces significant contralateral turning in MPTP intoxicated animals in the presence of a control siRNA. This behavior is fully antagonized when Engrailed is co-infused with Ndufs1 siRNA. Data expressed in net turns/min. $* P<0.05, * * P<0.01 ; \mathrm{n}=5-10$.

(d) Engrailed significantly induces amphetamine-induced contralateral turning in nonlesioned animals compared to sham-infused animals. $* * * P<0.001 ; \mathrm{n}=17$.

Figure 7 Engrailed protects against 6-OHDA and $\alpha$-synuclein A30P toxicity

(a) 6-OHDA decreased the number of TH-positive neurons by $59.35 \% \pm 2.54 \%$ (mean \pm s.e.m.) $(* P<0.001)$ compared to the non-treated side of each animal. The infusion of En1/En2 reduced cell loss to $17.81 \% \pm 6.12 \%$ ( $\# P<0.001$ ). Data are expressed as percentage of control, $\mathrm{n}=6-10$ animals/group. S, sham-infused animals; En, Engrailed-infused animals.

(b) Treatment with A30P $\alpha$-synuclein decreased the number of TH-positive neurons by $33.47 \% \pm 9.93 \% \mathrm{~s}(* \mathrm{P}=0.005)$ compared to the non-treated side and infused En fully protected (compared to saline, $\# P<0.001$ ). No difference was detectable between the $\alpha$ synuclein $\mathrm{A} 30 \mathrm{P} / \mathrm{En}$ and control groups $(P=0.46)$. Data are expressed in percentage of control, $\mathrm{n}=4-6$ animals/group. S, sham-infused animals; En, Engrailed-infused animals.

\section{REFERENCES}

1. Dauer, W. \& Przedborski, S. Parkinson's disease: mechanisms and models Neuron 39, 889-909 (2003).

2. Dawson, T.M. \& Dawson, V.L. Molecular pathways of neurodegeneration in Parkinson's disease Science 302, 819-822 (2003).

3. Schapira, A.H. Mitochondria in the aetiology and pathogenesis of Parkinson's disease. Lancet Neurol 7, 97-109 (2008).

4. Ang, S.L. Transcriptional control of midbrain dopaminergic neuron development. Development 133, 3499-3506 (2006).

5. Albéri, L., Sgadò, P. \& Simon, H. Engrailed genes are cell-autonomously required to prevent apoptosis in mesencephalic dopaminergic neurons. Development 131, 3229-3236 (2004).

6. Hanks, M., Wurst, W., Anson-Cartwright, L., Auerbach, A.B. \& Joyner, A.L. Rescue of the En-1 mutant phenotype by replacement of En-1 with En-2 Science 269, 679-682 (1995).

7. Sonnier, L., et al. Progressive loss of dopaminergic neurons in the ventral midbrain of adult mice heterozygote for Engrailed1 $J$ Neurosci 27, 1063-1071 (2007).

8. Prochiantz, A. \& Joliot, A. Can transcription factors function as cell-cell signalling molecules? . Nat Rev Mol Cell Biol 4, 814-819 (2003).

9. Brunet, I., et al. The transcription factor Engrailed-2 guides retinal axons Nature 438, 94-98 (2005).

10. Wizenmann, A., et al. Extracellular Engrailed participates in the topographic guidance of retinal axons in vivo. Neuron 64, 355-366 (2009). 
11. Richter, J.D. \& Klann, E. Making synaptic plasticity and memory last: mechanisms of translational regulation. Genes Dev 23, 1-11 (2009).

12. Nédélec, S., et al. Emx2 homeodomain transcription factor interacts with eukaryotic translation initiation factor 4E (eIF4E) in the axons of olfactory sensory neurons Proc Natl Acad Sci USA 101, 10815-10820 (2004).

13. Topisirovic, I. \& Borden, K.L.B. Homeodomain proteins and eukaryotic translation initiation factor 4E (eIF4E) : an unexpected relationship. Histol Histopathol 20, 1275-1284 (2005).

14. Di Nardo, A.A., et al. Dendritic localization and activity-dependent translation of Engrailed1 transcription factor. Mol Cell Neurosci 35, 230-236 (2007).

15. Alvarez-Fischer, D., et al. Characterization of the striatal 6-OHDA model of Parkinson's disease in wild type and alpha-synuclein-deleted mice. Exp Neurol 210, 182-193 (2008).

16. Recchia, A., et al. Generation of a alpha-synuclein-based rat model of Parkinson's disease. Neurobiol Dis 30, 8-18 (2008).

17. Höglinger, G.U., et al. Chronic systemic complex I inhibition induces a hypokinetic multisystem degeneration in rats. $J$ Neurochem 84, 491-502 (2003).

18. Marc, P., et al. Genome-wide analysis of mRNAs targeted to yeast mitochondria EMBO Rep 3, 159-164 (2002).

19. Ricci, J.E., et al. Disruption of mitochondrial function during apoptosis is mediated by caspase cleavage of the p75 subunit of complex I of the electron transport chain Cell 117, 773-786 (2004).

20. Dieteren, C.E., et al. Subunits of mitochondrial complex I exist as part of matrix- and membrane-associated subcomplexes in living cells J Biol Chem 283, 34753-34761 (2008).

21. De Toni, A., et al. Regulation of survival in adult hippocampal and glioblastoma stem cell lineages by the homeodomain-only protein HOP. Neural Dev 3, 13 (2008).

22. Joliot, A. \& Prochiantz, A. Transduction peptides: from technology to physiology. Nat Cell Biol 6, 189-196 (2004).

23. Fuchs, J., et al. The transcription factor PITX3 is associated with sporadic Parkinson's disease. Neurobiol Aging 30, 731-738 (2009).

24. Haubenberger, D., et al. Association of transcription factor polymorphisms PITX3 and EN1 with Parkinson's disease. Neurobiol Aging 32, 302-307 (2011).

25. Flanagan, J.G. Neural map specification by gradients. Curr Opin Neurobiol 16, 59-66 (2006).

26. Boldogh, I.R. \& Pon, L.A. Mitochondria on the move. Trends Cell Biol 17, 502-510 (2007).

27. Abou-Sleiman, P.M., Muqit, M.M. \& Wood, N.W. Expanding insights of mitochondrial dysfunction in Parkinson's disease. Nat Rev Neurosci 7, 207-219 (2006).

28. Iaccarino, C., et al. Apoptotic mechanisms in mutant LRRK-2mediated cell death Hum Mol Genet 16, 1319-1326 (2007).

29. Bénit, P., et al. Mutant NDUFS3 subunit of mitochondrial complex I causes Leigh syndrome. J Med Genet 41, 14-17 (2004).

30. Iuso, A., et al. Dysfunctions of cellular oxidative metabolism in patients with mutations in the NDUFS1 and NDUFS4 genes of complex I $J$ Biol Chem 281, 10374-10380 (2006).

31. Ekstrand, M.I., et al. Progressive parkinsonism in mice with respiratory-chaindeficient dopamine neurons. Proc Natl Acad Sci U S A 104, 1325-1330 (2007).

32. De Vos, K.J., Grierson, A.J., Ackerley, S. \& Miller, C.C. Role of axonal transport in neurodegenerative diseases. Annu Rev Neurosci 31, 151-173 (2008).

33. Brundin, P., Li, J.Y., Holton, J.L., Lindvall, O. \& Revesz, T. Research in motion: the enigma of Parkinson's disease pathology spread. Nat Rev Neurosci 9, 741-745 (2008). 
34. Kadkhodaei, B., et al. Nurr1 is required for maintenance of maturing and adult midbrain dopamine neurons. J Neurosci 29, 15923-15932 (2009).

35. Chung, C.Y., et al. The transcription factor orthodenticle homeobox 2 influences axonal projections and vulnerability of midbrain dopaminergic neurons. Brain 133, 20222031 (2010).

36. Di Salvio, M., et al. Otx2 controls neuron subtype identity in ventral tegmental area and antagonizes vulnerability to MPTP. Nat Neurosci 13, 1481-1488 (2010).

37. Ibad, R.T., et al. Otx2 promotes the survival of damaged adult retinal ganglion cells and protects against excitotoxic loss of visual acuity in vivo. $J$ Neurosci 31, 5495-5503 (2011).

38. Joshi, R.L., et al. Cell non-autonomous functions of homeoproteins in neuroprotection in the brain. FEBS Lett 585, 1573-1578 (2011).

39. Topisirovic, I., et al. Eukaryotic translation initiation factor 4E activity is modulated by HOXA9 at multiple levels Mol Cell Biol 25, 1100-1112 (2005).

40. Wegrzyn, J., et al. Function of mitochondrial Stat3 in cellular respiration. Science 323, 793-797 (2009).

41. She, H., et al. Direct regulation of complex I by mitochondrial MEF2D is disrupted in a mouse model of Parkinson disease and in human patients. J Clin Invest 121, 930-940 (2011).

42. Tatton, N.A. \& Kish, S.J. In situ detection of apoptotic nuclei in the substantia nigra compacta of 1-methyl-4-phenyl-1,2,3,6-tetrahydropyridine-treated mice using terminal deoxynucleotidyl transferase labelling and acridine orange staining Neuroscience 77, 10371048 (1997).

\section{ONLINE METHODS}

Animal treatments. Animals were treated in accordance with the guide for the care and use of laboratory animals (National Institutes of Health, Bethesda, MD) and the European Directive N ${ }^{\circ} 86 / 609$. Nine week-old male C57BL/6J mice (Janvier, France) were infused with Engrailed as described ${ }^{7}$. Briefly, En1/En2 recombinant proteins produced in bacteria were dialyzed against $0.9 \% \mathrm{NaCl}$, and osmotic mini pumps (Alzet model 1002, Charles River Laboratories, France) were filled with $75 \mu \mathrm{g} / \mathrm{ml}$ of each protein (4.5 $\mu \mathrm{M}$ total Engrailed) and $1.5 \mu \mathrm{g} / \mu \mathrm{l}$ colominic acid in saline. Mice were infused for 14 days into a region dorsal to the SNpc (a/p: $-3.3 \mathrm{~mm} ; \mathrm{m} / \mathrm{l}:-1 \mathrm{~mm} ; \mathrm{d} / \mathrm{v}:-3 \mathrm{~mm}$ relative to bregma) according to the atlas of Franklin and Paxinos ${ }^{42}$, with a solution containing En1/En2/colominic acid or vehicle, respectively. For the siRNA experiments, $1 \mu \mathrm{M}$ of Penetratin-coupled siRNA against Ndufs1 or a control siRNA were added to the respective minipump solution containing En1/En2/colominic acid or vehicle ${ }^{20}$. Five days after pump implantation, mice received MPTP-HCl (Sigma-Aldrich) at a concentration of $30 \mathrm{mg} / \mathrm{kg}$ once a day (i.p.) or equal volumes of saline for 5 consecutive days ('subchronic paradigm'; ${ }^{41}$ ). For TH-positive cell 
counting and HPLC, mice were sacrificed on day 21, one week after termination of Engrailed delivery. Intrastriatal 6-OHDA injection $(4 \mu \mathrm{g}$ in $2 \mu \mathrm{l})$ was performed as described ${ }^{15}$ at the same session when pumps with Engrailed or vehicle were implanted in the midbrain. Animals were sacrificed 14 days after treatment. The penetratin coupled $\alpha$-synuclein A30P protein (4 $\mu \mathrm{g})$ was injected in the SNpc followed by pump implantation to infuse Engrailed or vehicle. Animals were sacrificed 2 weeks after treatment.

Cell cultures. Primary mesencephalic cultures of E14.5 rat and mouse embryos were prepared as reported ${ }^{43,44}$. For $\mathrm{MPP}^{+}$, rotenone and 3-NP experiments, cells were plated into well coated with polyethylenimine and cultured in N5 medium ${ }^{44}$ supplemented with $5 \%$ horse serum, and $0.5 \%$ FCS, except for the first 3 days when $2.5 \%$ FCS was added to facilitate cell attachment. Cells were treated with $2 \mu \mathrm{M}$ AraC (Sigma-Aldrich) to block astrocyte growth and $2 \mu \mathrm{M}$ MK801 (Sigma-Aldrich) to prevent excitotoxic cell damage. Toxins were added between days 4 and 6 at a concentration of $3 \mu \mathrm{M}\left(\mathrm{MPP}^{+}\right), 100 \mu \mathrm{M}(3-\mathrm{NP})$ and $50 \mathrm{nM}$ (rotenone, only day 4 to day 5). The total number of TH-positive neurons in controls was about $0.7 \%$ of all neurons as previously described ${ }^{45}$. For all other experiments, cells were cultured in Neurobasal medium (Gibco) supplemented with $500 \mu \mathrm{M}$ glutamine, 25 $\mu \mathrm{M}$ glutamate and $25 \mu \mathrm{M}$ aspartate and B27 (Gibco) in wells coated with poly-L-ornithine and laminine (Sigma). After 5 days, cells were treated as indicated and subjected to Western blot analysis as indicated below. Where indicated, actinomycin D was used at $5 \mu \mathrm{g} / \mathrm{ml}$ and En1 was preincubated with 67 -fold molar excess of an anti-Engrailed antibody $\left(86 / 8,{ }^{7}\right)$ for 1 hour.

Immunohisto/cytochemistry. Immunohistochemistry (IHC) was performed on free-floating cryosections $(20 \mu \mathrm{m})$ encompassing the entire midbrain of paraformaldehyde-fixed brains ${ }^{46}$. For Ndufs1, Ndufs 3 and Cox IV, sections were incubated for $30 \mathrm{~min}$ at $100^{\circ} \mathrm{C}$ in $100 \mathrm{mM}$ Tris- $\mathrm{HCl} \mathrm{pH} 9.5$ and 5\% urea prior to stainings. The primary antibodies for IHC and immunocytochemistry (ICC) with cultured cells were: anti-TH rabbit polyclonal antibody (Pel-Freez Biologicals), anti-Engrailed rabbit polyclonal antibody 86/8 (produced in house), anti-Ndufs3 mouse monoclonal (Abcam), anti-Ndufs 1 mouse polyclonal (Abcam); anti-NeuN (neuronal nuclei) streptavidin conjugated mouse polyclonal antibody (Chemicon) and antiCox IV rabbit polyclonal antibody (Cell Signaling). For IHC, the secondary antibodies used were: anti-rabbit-HRP (Vector Lab), anti-mouse-HRP (Vector Lab). Staining was revealed with chromogen diaminobenzidine (DAB). For ICC, the secondary antibodies used were: 
donkey anti-mouse conjugated with Cy3 (Sigma), goat anti-rabbit conjugated with Alexa 488 (Invitrogen), Biotin-conjugated $\mathrm{Cy} 3$ or $\mathrm{Cy} 5$ and goat anti-mouse conjugated with Alexa 488 (Invitrogen).

Quantification of in vitro neuron survival. Survival of mDA neurons was quantified by counting the number of TH positive neurons. All neurons regardless of their neurotransmitter phenotype were identified by NeuN immunofluorescence staining.

Cell counting. TH-positive neurons were visualized in bright field (Nikon Optiphot-2) and quantified stereologically on regularly spaced sections covering the mesencephalon from the rostral pole of the SNpc to the locus coeruleus (Mercator T4.18 stereology software) ${ }^{17}$. The SNpc was identified according to established anatomical landmarks ${ }^{42}$. Cell loss was verified by Nissl counterstaining.

Quantification of Ndufs1 and Ndufs3 staining in the SNpc of $E n 1^{+/} E n 2^{+/+}$mice. IHCDAB staining for Ndufs1 and Ndufs3 was performed as above using free-floating cryosections $(20 \mu \mathrm{m})$ of the entire midbrain of one year old $E n 1^{+/} E n 2^{+/+}$mice and wt littermates (4 mice for each group). The quantification of optical density was done using Mercator T4.18 software (ExploraNova, La Rochelle, France). For each section, background was adjusted. Cells (40-60 per side) were chosen randomly and optical density was measured at 20x magnification over the surface of single neurons. Ndufs3 staining in the control region (oculomotor nucleus) was analyzed accordingly on the same slices.

The quantification of Ndufs3 in $\mathrm{mDA}$ neurons in SNpc was also performed by immunofluorescence using free floating coronal vibratome sections $(70 \mu \mathrm{m})$ of one year old $E n 1^{+/-} E n 2^{+/+}$mice and $w t$ littermates $(\mathrm{n}=3)$. Briefly, after antigen retrieval, sections were permeabilized, blocked, incubated in mouse anti-Ndufs 3 and rabbit anti-TH and then in goat anti-mouse and goat anti-rabbit antibodies conjugated respectively to Alexa Fluor 488 and 555. Images were recorded on a Leica TCS SP2 confocal microscope (Leica Microsystems) equipped with a $40 \mathrm{x}$ oil-immersion objective $(\mathrm{NA}=1.00)$. Gains were adjusted to avoid saturation in pixels intensity. Two brain sections within the same region of the SNpc and spaced apart by $140 \mu \mathrm{m}$ were selected for each animal (3 mice par group). In each section, 4 to 6 fields covering the whole SNpc were then acquired with constant imaging parameters at a depth of 10 to $20 \mu \mathrm{m}$ below the coverslip. Altogether a total of 29 and 33 fields were acquired for $w t$ and $E n 1^{+/-} E n 2^{+/+}$mice, respectively. The quantitative analysis was performed in Image 
J. TH images were first smoothed and thresholded to yield a binary image which was then used as a mask to measure Ndufs 3 staining intensity only in TH-positive structures (mDA neurons). Ndufs3 staining intensity was also quantified in TH-positive neurons in the VTA of wt and $E n 1^{+/-} E n 2^{+/+}$on the same sections (Supplementary Fig. 4).

Metabolic labeling of synaptoneurosomes and complex I, II and V immunocapture. Synaptoneurosomes prepared from ventral midbrains of 4 week-old C57BL/6 mice by filtration ${ }^{47}$ were incubated for $1 \mathrm{~h}$ at $37^{\circ} \mathrm{C}$ with $\left[{ }^{35} \mathrm{~S}\right]$ methionine $/\left[{ }^{35} \mathrm{~S}\right]$ cysteine (Promix; Amersham) and either Engrailed or vehicle and subjected to 2-D SDS-PAGE and autoradiography. Newly translated proteins were identified by liquid chromatography electrospray ionization tandem mass spectrometry (LC-ESI-MS/MS). For the immunocapture of complex I, II and V, mitochondria were isolated from synaptoneurosomes and immunoprecipitations of complex I, II and V were performed following the manufacturer's protocol (MitoProfile complex I, II and V Immunocapture Kit, MitoScience). The materiel was analyzed by SDS-PAGE and bands corresponding to subunits of the respective complexes were visualized by phosphorimager. In the case of complex I, proteins corresponding to visible bands were identified by LC-ESI-MS/MS. For complex II and V, protein bands were identified according to the respective molecular weights as known from the literature. Quantification of complex I subunits was done using ImageJ. Background was substracted and the densitometric value of engrailed-treated samples compared to control determined.

Mitochondrial activity. Complex I, complex IV and citrate synthase activities were measured as described ${ }^{17}$. In brief, extracts prepared from synaptoneurosomes treated or not with En1 $(15 \mathrm{nM})$ for $1 \mathrm{~h}$ at $37^{\circ} \mathrm{C}$, were mixed with $10 \mathrm{mM}$ Tris- $\mathrm{HCl} \mathrm{pH} \mathrm{7.2,} 225 \mathrm{mM}$ mannitol, $75 \mathrm{mM}$ saccharose and $0.1 \mathrm{mM}$ EDTA. Complex I and IV activities were analyzed spectophotometrically by measuring the rate of NADH (complex I) and cytochrome c (complex IV) oxidation during $3 \mathrm{~min}$ at $37^{\circ} \mathrm{C}$ in an assay mixture containing $40 \mu \mathrm{g}$ protein of synaptoneurosomal extracts. Complex I activity was measured in the absence and the presence of $2 \mu \mathrm{M}$ rotenone, and the rotenone-sensitive activity was attributed to complex I. Citrate synthase activity was measured spectophotometrically using Acetyl-CoA and oxaloacetate during $0.8 \mathrm{~min}$ at $37^{\circ} \mathrm{C}$. 
siRNA coupling to Penetratin and testing in vivo. A predesigned siRNA against Ndufs1 (Target sequence: 5'-ATGCATGAAGATATTAATGAA-3'; Qiagen) or control siRNA with a Thio-C6-linker modification on the 5' end of the sense strand was incubated with an equimolar quantity of Tris(2-carboxyethyl)phosphine hydrochloride (Sigma) before addition of activated Penetratin 1 (Q-Biogene) in two-fold molar excess and the mix was heated at $65^{\circ} \mathrm{C}$ and further incubated at $37^{\circ} \mathrm{C}$ before aliquoting and freezing. For in vivo testing, a $1 \mu \mathrm{M}$ solution of Penetratin-coupled Ndufs1 siRNA or control siRNA was infused in 8-week-old C57BL/6 mice as described above using 3-day micro-osmotic pumps. The ventral midbrain encompassing the SNpc was dissected 3 days after pump implantation and processed for western blot analysis. This resulted in moderate but significant Ndufs1 downregulation (Supplementary Fig. 6).

Western blot analysis. Western blot analyses were performed using standard procedures with the following primary antibodies: anti-Ndufs1 rabbit polyclonal (Proteintech), anti-Ndufs3 mouse monoclonal (Abcam), anti-COX IV rabbit polyclonal (Cell Signaling) and anti-actin goat polyclonal (Santa Cruz). The bands were quantified by densitometry.

HPLC. For DA measurements, striatal extracts were prepared and analyzed by HPLC using a reverse phase column (Nucleosil 120-3 C18; Knauer, Berlin, Germany) and electrochemical detection as described ${ }^{15}$. Data were recorded and quantified using HPLC Chromeleon computer system (Dionex, Germany).

Turning behavior. Amphetamine-induced rotation behavior was measured as previously described $^{49}$. Mice received $5 \mathrm{mg} / \mathrm{kg}$ D-amphetamine hemisulfate salt (Sigma-Aldrich) and were placed after $20 \mathrm{~min}$ into individual glass bowls. Contralateral and ipsilateral turning were recorded for $5 \mathrm{~min}$. Results are expressed as net turns/min. Significant contralateral turning indicates an increase in nigrostriatal dopaminergic activity on the infused ipsilateral side $^{49}$.

Quantification of DAT activity. DAT activity was determined in cultured cells treated or not with Engrailed by measuring $\left[{ }^{3} \mathrm{H}\right]$-dopamine uptake as described ${ }^{45}$. Engrailed treatment did not alter DAT activity (Supplementary Fig. 1). 
Statistical analysis. Data are expressed as mean \pm standard error of the mean (s.e.m) if not otherwise indicated. All in vitro experiments were performed at least in triplicate. Experimental data were compared by one-way ANOVA and a post-hoc Student-NewmanKeuls test for pair-wise comparisons and post-hoc Dunnett's test when compared to controls. $P<0.05$ was considered significant.

43. Franklin, K.B.J. \& Paxinos, G. The mouse brain in stereotaxic coordinates Academic Press (1997).

44. Salthun-Lassalle, B., Hirsch, E.C., Wolfart, J., Ruberg, M. \& Michel, P.P. Rescue of Mesencephalic Dopaminergic Neurons in Culture by Low-Level Stimulation of VoltageGated Sodium Channels J Neurosci 24, 5922-5930 (2004).

45. Kawamoto, J.C. \& Barrett, J.N. Cryopreservation of primary neurons for tissue culture Brain Res 384, 84-93 (1986).

46. Douhou, A., Troadec, J.D., Ruberg, M., Raisman-Vozari, R. \& Michel, P.P. Survival promotion of mesencephalic dopaminergic neurons by depolarizing concentrations of $\mathrm{K}+$ requires concurrent inactivation of NMDA or AMPA/kainite receptors $J$ Neurochem $\mathbf{7 8 1}$, 163-174 (2001).

47. Hirsch, E.C., Graybiel, A.M. \& Agid, Y.A. Melanized dopaminergic neurons are differentially susceptible to degeneration in Parkinson's disease. Nature 334, 345-348 (1988).

48. Hollingsworth, E.B., et al. Biochemical characterization of a filtered synaptoneurosome preparation from guinea pig cerebral cortex: cyclic adenosine $3^{\prime}: 5^{\prime}$ monophosphate-generating systems, receptors, and enzymes. J Neurosci 5, 2240-2253 (1985). 49. Villasana, L.E., Klann, E. \& Tejada-Simon, M.V. Rapid isolation of synaptoneurosomes and postsynaptic densities from adult mouse hippocampus $J$ Neurosci Methods 158, 30-36 (2006).

50. Iancu, R., Mohapel, P., Brundin, P. \& Paul, G. Behavioral characterization of a unilateral 6-OHDA-lesion model of Parkinson's disease in mice. Behav Brain Res 162, 1-10 (2005). 
a

\section{Complex I}

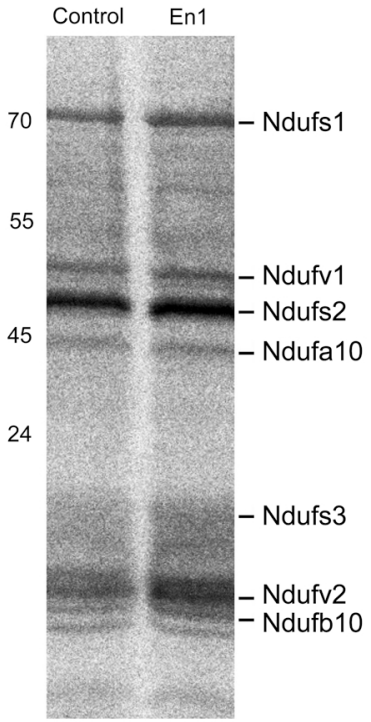

b

\begin{tabular}{|c|c|}
\hline & En1/ Control \\
\hline Ndufs1 & 1.43 \\
\hline Ndufv1 & 1.17 \\
\hline Ndufs2 & 1.16 \\
\hline Ndufa10 & 1.17 \\
\hline Ndufs3 & 1.68 \\
\hline Ndufv2 & 1.23 \\
\hline Ndufb10 & 1.16 \\
\hline
\end{tabular}

C

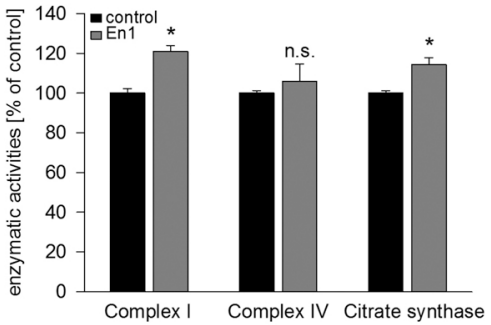

Fig. 2 
$a$

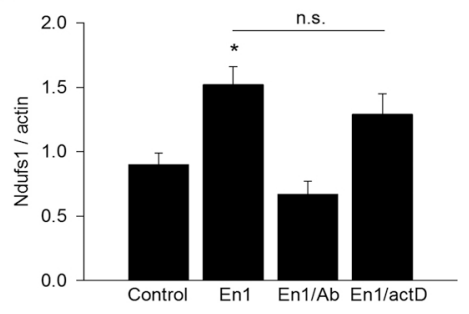

Ndufs 1

Actin b

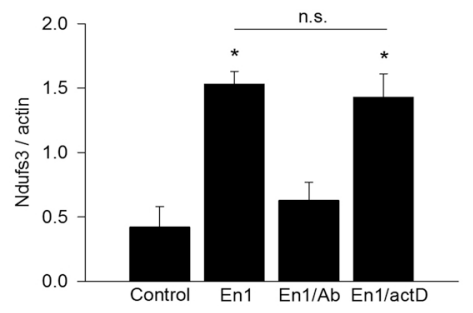

Ndufs3

Actin
C

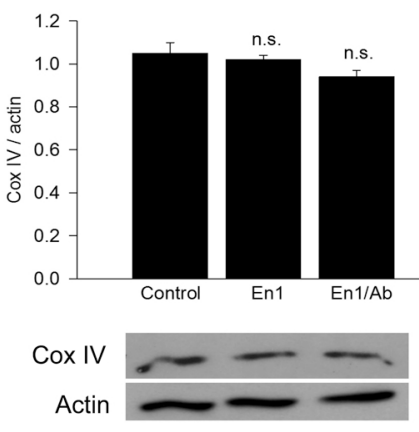

Fig. 3 
a

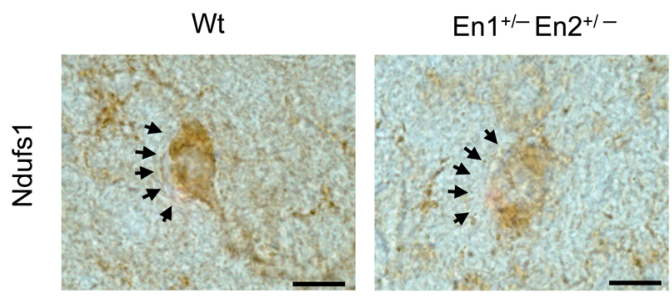

C

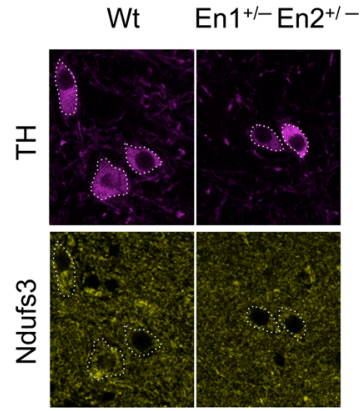

b
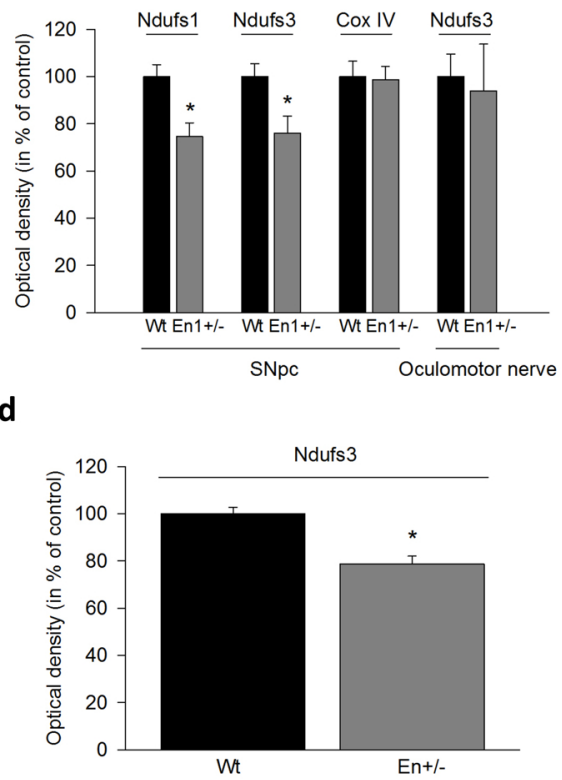

Fig. 4 
b

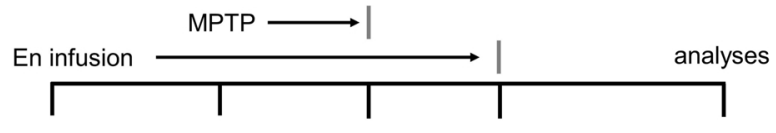

$\begin{array}{llll}\text { Day } 1 & \text { Day } 5 & \text { Day } 9 & \text { Day } 14\end{array}$

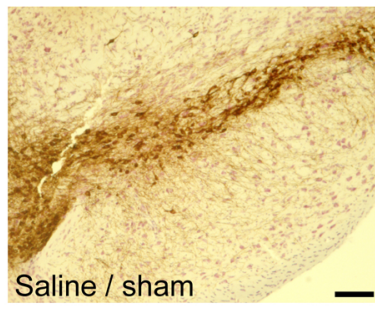

Saline / Engrailed

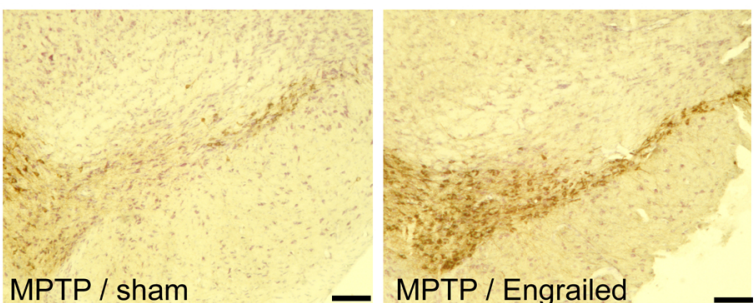

d

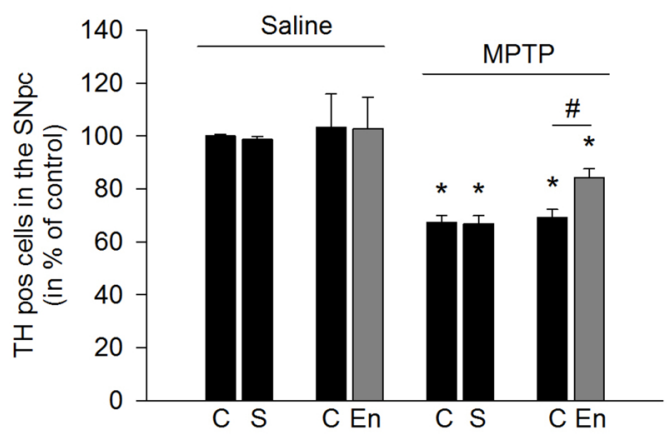

C
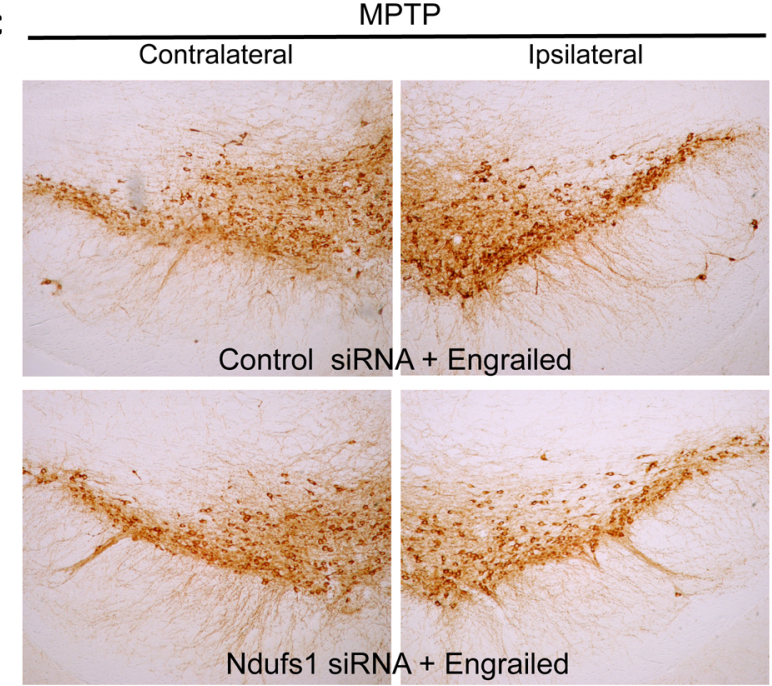

e

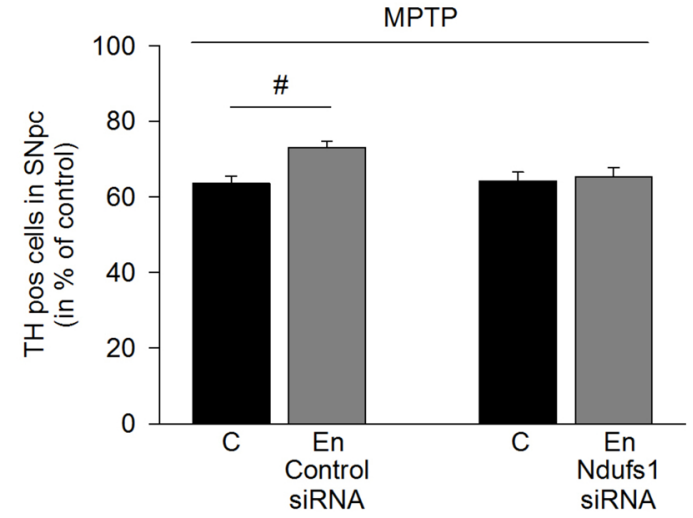

Fig. 5 
a

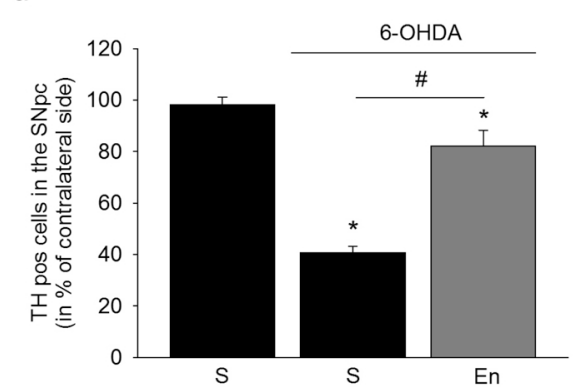

b

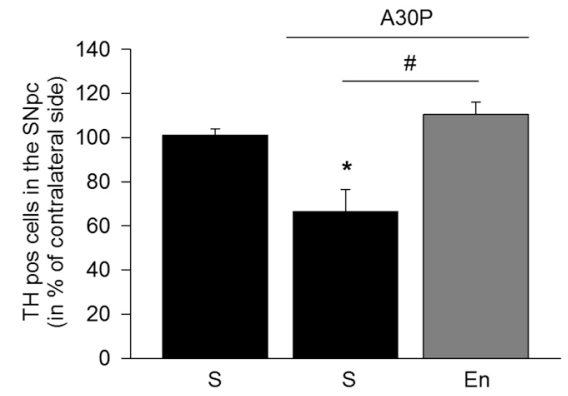

Fig. 7 


\section{Supplementary Information Titles}

Please list each supplementary item and its title or caption, in the order shown below. Please include this form at the end of the Word document of your manuscript or submit it as a separate file.

Note that we do NOT copy edit or otherwise change supplementary information, and minor (nonfactual) errors in these documents cannot be corrected after publication. Please submit document(s) exactly as you want them to appear, with all text, images, legends and references in the desired order, and check carefully for errors.

\section{Journal: Nature Neuroscience}

\begin{tabular}{|l|l|}
\hline Article Title: & $\begin{array}{l}\text { Engrailed protects mouse midbrain dopaminergic neurons against } \\
\text { mitochondrial complex I insults }\end{array}$ \\
\hline $\begin{array}{l}\text { Corresponding } \\
\text { Author: }\end{array}$ & Alain Prochiantz \\
\hline & \\
\hline
\end{tabular}

\begin{tabular}{|c|c|}
\hline $\begin{array}{l}\text { Supplementary Item } \\
\text { \& Number } \\
\text { (add rows as necessary) }\end{array}$ & Title or Caption \\
\hline Supplementary Figure 1 & Engrailed treatment has no effect on DAT activity. \\
\hline Supplementary Figure 2 & $\begin{array}{l}\text { Quantification of neurons and astrocytes in mesencephalic } \\
\text { cultures }\end{array}$ \\
\hline Supplementary Figure 3 & $\begin{array}{l}\text { Engrailed does not affect the synthesis of complex II or } \\
\text { complex V subunits }\end{array}$ \\
\hline Supplementary Figure 4 & $\begin{array}{l}\text { Ndufs } 3 \text { expression in mDA neurons in the VTA of wt and } \\
E n 1^{+/} \text {mice }\end{array}$ \\
\hline Supplementary Figure 5 & $\begin{array}{l}\text { The number of TH-negative neurons remains constant upon } \\
\text { MPTP treatment }\end{array}$ \\
\hline Supplementary Figure 6 & Verification of siRNA used against Ndufs 1 \\
\hline
\end{tabular}


Alvarez-Fischer et al.

\section{SUPPLEMENTARY INFORMATION}

Engrailed protects mouse midbrain dopaminergic neurons against mitochondrial complex I insults

Daniel Alvarez-Fischer, Julia Fuchs, François Castagner, Olivier Stettler, Olivia Massiani Beaudoin, Kenneth L. Moya, Colette Bouillot, Wolfgang H. Oertel, Anne Lombès, Wolfgang Faigle, Rajiv L. Joshi, Andreas Hartmann \& Alain Prochiantz 


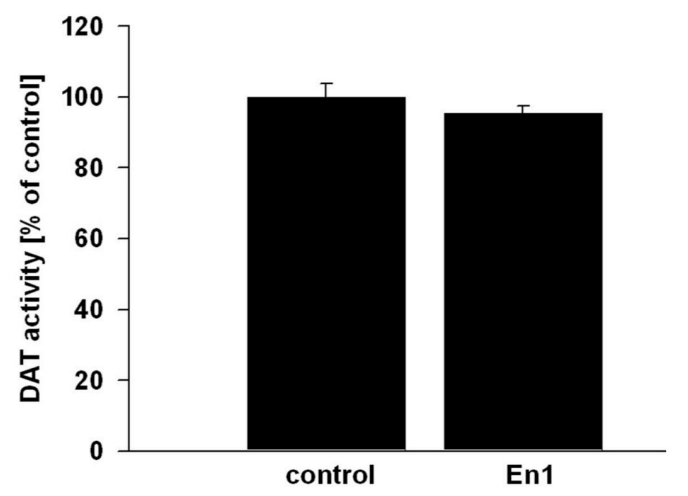

Supplementary Fig. 1 Engrailed treatment has no effect on DAT activity.

DAT-activity was measured by the uptake of $\left[{ }^{3} \mathrm{H}\right]$-dopamine in mesencephalic cultures treated or not with Engrailed $(3 \mathrm{nM})$. The cultures were preincubated for $10 \mathrm{~min}$ with $500 \mu 1$ PBS, $5 \mu \mathrm{M}$ glucose and $100 \mu \mathrm{M}$ ascorbic acid prior to the addition of $50 \mathrm{nM}\left[{ }^{3} \mathrm{H}\right]$-dopamine $(30 \mathrm{mCi} / \mathrm{mmol})$. The incubation was stopped after $15 \mathrm{~min}$ by two rapid washes with cold PBS. The cells were scraped off and radioactivity was measured in a liquid scintillation spectrophotometer. Blank values, determined with $5 \mu \mathrm{M}$ of the dopamine uptake inhibitor GBR-12909, represented less than $10 \%$ of total uptake in control conditions. Data are expressed in percentage of control values, which corresponds to $24,400 \mathrm{cpm}$. 


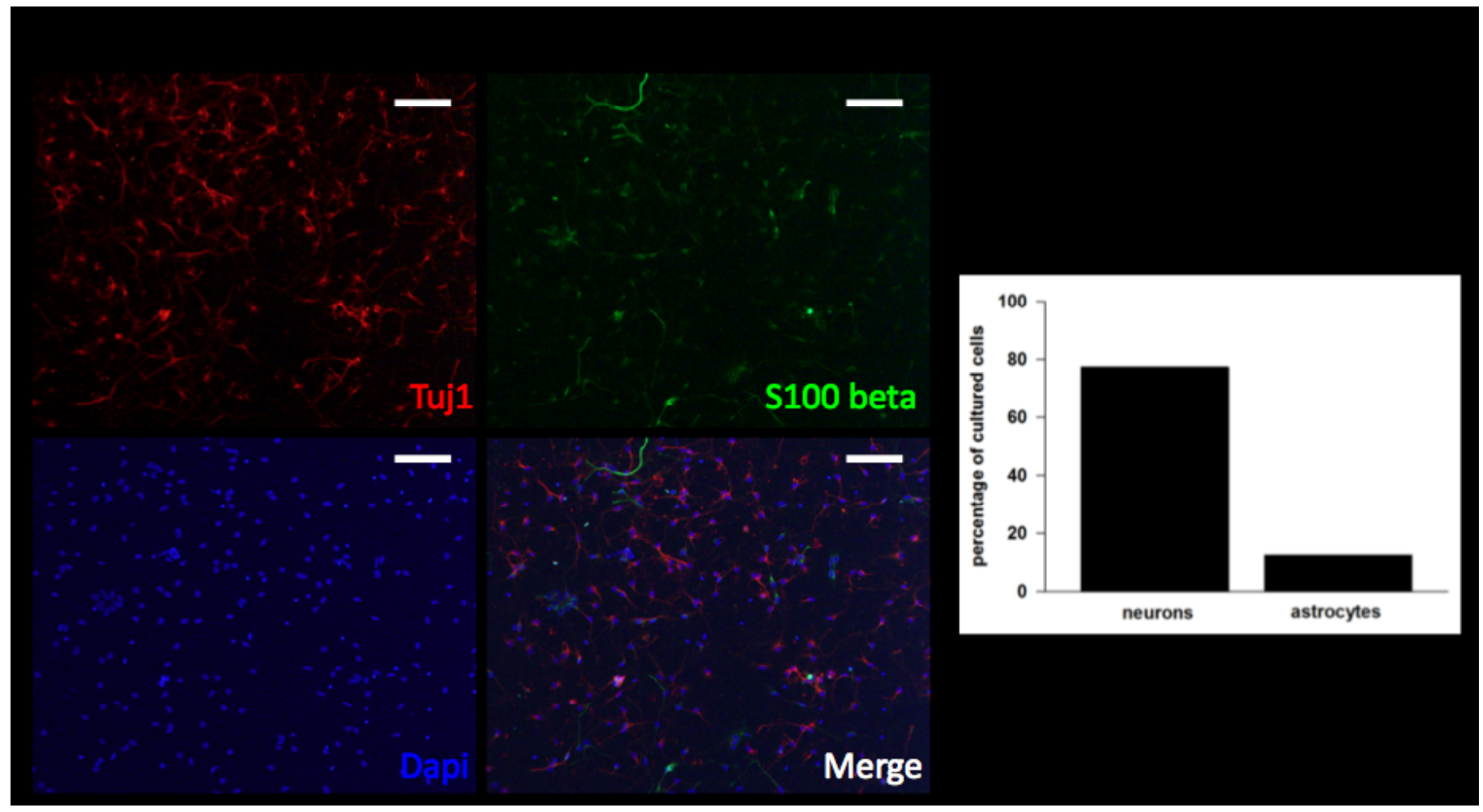

Supplementary Fig. 2 Quantification of neurons and astrocytes in mesencephalic cultures Neuronal cultures were fixed after 5 days in vitro and stained with Tuj1, a neuronal marker, and S100 beta, a glial marker. Scale bar, $100 \mu \mathrm{m}$. The graph depicts the percentage of each cell type. 
a

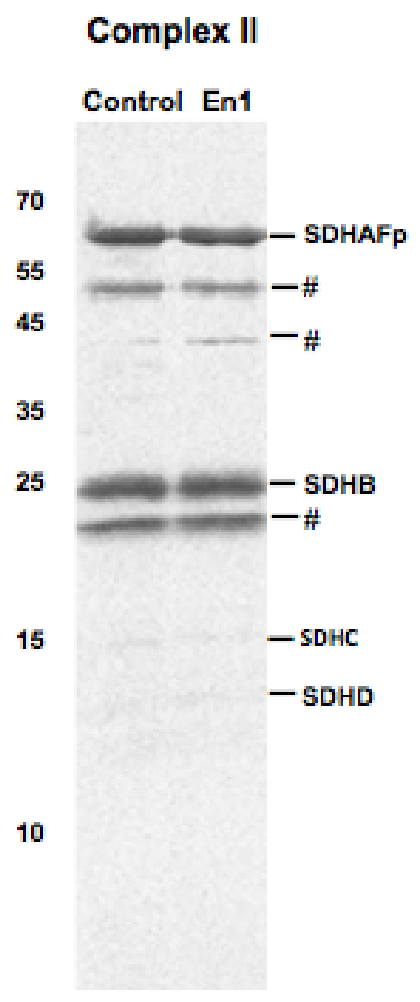

b

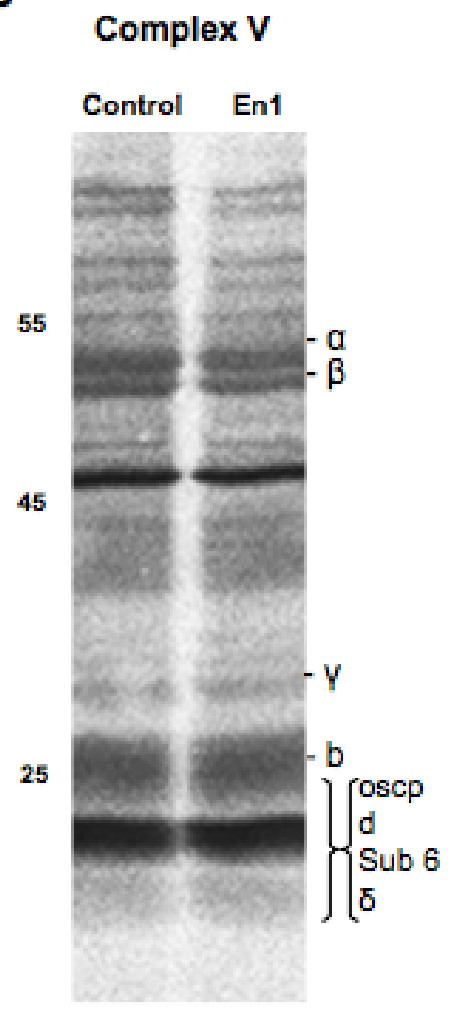

Supplementary Fig. 3 Engrailed does not affect the synthesis of complex II or complex V subunits

Metabolic labeling of midbrain synaptoneurosomes followed by complex II and complex V immunocapture and SDS-PAGE does not reveal any change upon Engrailed treatment. 


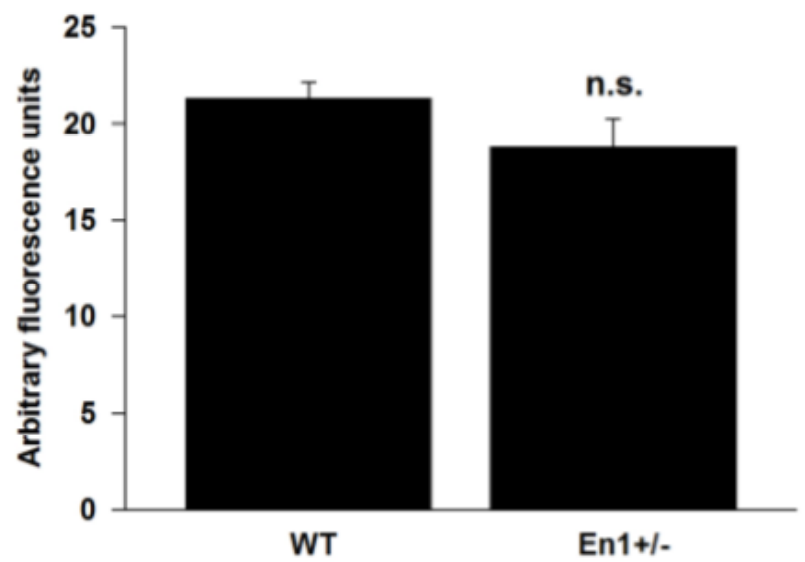

Supplementary Fig. 4 Ndufs 3 expression in mDA neurons in the VTA of wt and $E n 1^{+/-}$mice Ndufs3 levels in TH positive neurons in the VTA area were quantified as for mDA neurons in the SNpc area using the same sections as described in the legend of Fig. 4. The values for wt and $E n 1^{+/-}$mice are not significantly different. 


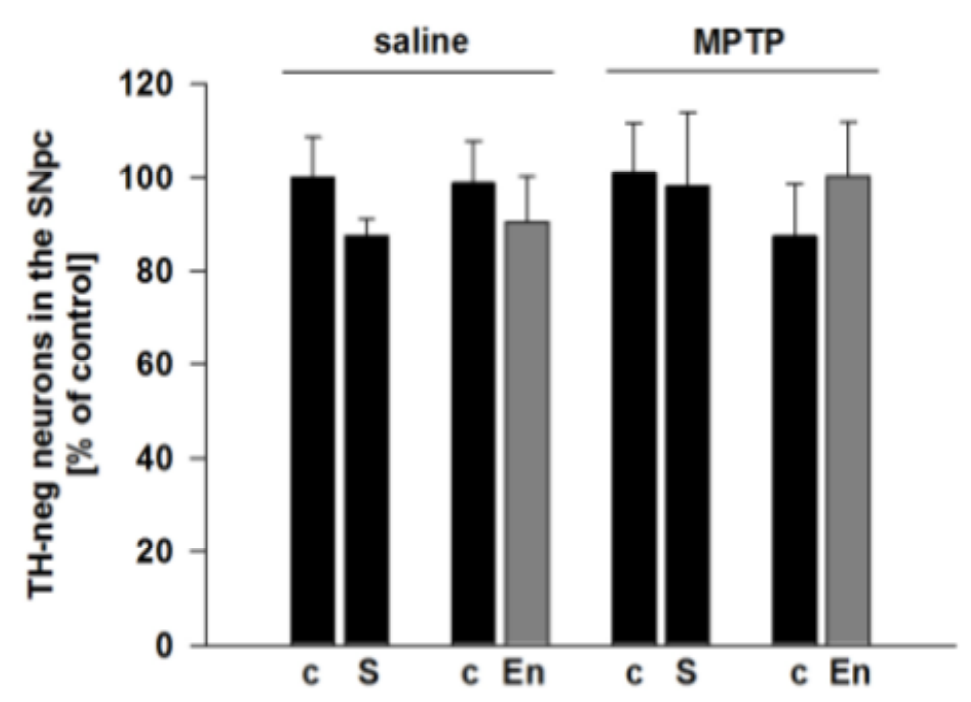

Supplementary Fig. 5 The number of TH-negative neurons remains constant upon MPTP treatment

The non-infused side of control mice injected with saline was set as $100 \%$ of TH-negative, Nissl-positive cells and used for comparison with all other conditions. As expected MPTP did not affect the number of TH-negative neurons indicating that differences seen in TH-positive neurons are true cell loss and not to a reduction in TH immunostaining. No conditions showed a significant difference compared to controls. Data are expressed in percentage of control, $n=$ 6-10 animals/group. c, contralateral, non-infused side; S, sham-infused side; En, Engrailedinfused side. 
a

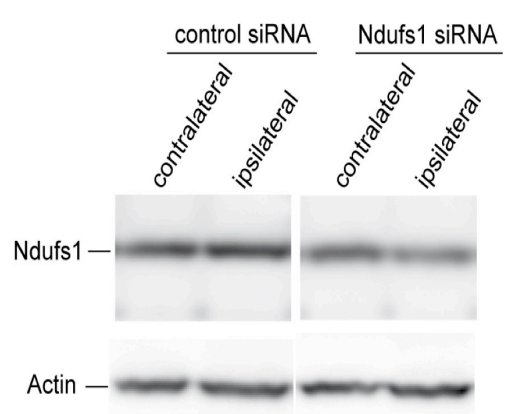

b

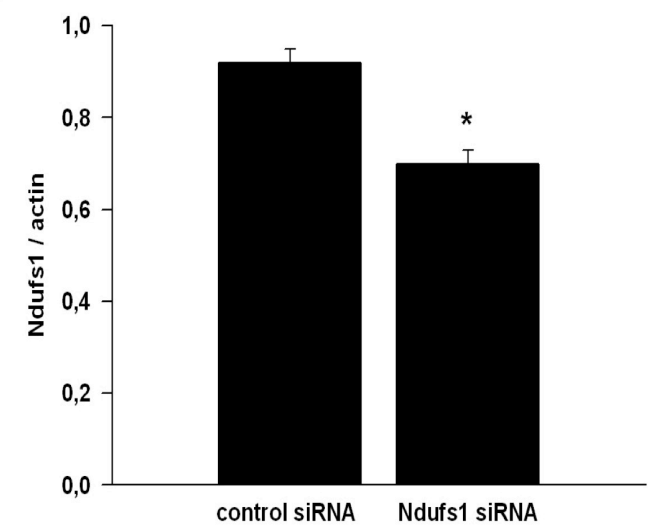

Supplementary Fig. 6 Verification of siRNA used against Ndufs1

(a) Western blot analysis of siRNA infused ventral midbrain extracts. Penetratin-coupled siRNA against Ndufs1 or control siRNA were infused for three days with a minipump into a region dorsal to the substantia nigra. The Western blots shows decreased amounts of Ndufs1 as compared to a control siRNA. (b) Quantification of Western blot analysis. The average ipsilateral versus contralateral ratio of Ndufs1 levels normalized to actin was calculated for each condition. Ndufs1 siRNA decreased Ndufs1 protein level on the infused side as compared to the contralateral side by about $30 \%$. ${ }^{*} \mathrm{P}<0.05(\mathrm{n}=3-4)$. 